\title{
Synthesis and Antimicrobial Activity of 1,4-Naphthoquinones Derivatives with [1,2,4]-Triazole- 3-thione Substitution
}

\author{
Y. U. SHAKH, I. ROMANENKO, M. SLESARCHUK, V. SYNGAEVSKY, O. KOVALCHUK ${ }^{1}$, K. BOLIBRUKH, A. KARKHUT, \\ L. BOLIBRUKH, I. GUBYTSKA, O. KOMAROVSKA-POROKHNYAVETS, S. POLOVKOVYCH* AND V. NOVIKOV \\ Department of Technology of Biologically Active Substances, Pharmacy and Biotechnology, National University "Lviv \\ Polytechnic", 79013, Lviv, ${ }^{1}$ Scientific-Research Expert-Crimynalistic Centre, Ministry of Internal Affairs of Ukraine, 79007, \\ Lviv, Ukraine
}

Shakh, et al.: Synthesis and Antimicrobial Property Investigation of 1,4-Naphthoquinone Derivatives

\begin{abstract}
The aim of the work was the synthesis of new S-, N-containing heterocyclic naphthoquinone derivatives and evaluation of antimicrobial activity, which is important in terms of finding new drugs. The implementation of this approach can be made by nucleophilic substitution between $\mathbf{N}$, S-bifunctional heterylaminothiotriazoles 2,3 and 2,3-dichloro-1,4-naphthoquinone 1. So the reaction between 2,3-dichloro-1,4-naphthoquinones and 4-amino-5-(2-methyl-furan-3-yl)-2,4-dihydro-[1,2,4]triazole-3-thione was investigated. It was established that the use of dimethylformamide as the reaction medium leads to the formation of two products with dominating yield of S-substitution products. Investigation of antimicrobial activity of the synthesized compounds showed that cultures of Escherichia coli, Aspergillus niger and Candida tenuis are not sensitive to 1,4-naphthoquinone heterocyclic derivatives $4,5,6,7$. But compounds 5,7 showed antibacterial activity with respect to Staphylococcus aureus and Mycobacterium luteum.
\end{abstract}

Key words: 1,4-naphthoquinones, nucleophilic substitution, antimicrobial activity

Synthesis of new S-, N-containing heterocyclic molecules is important in terms of searching new biologically active substances. In particular, compounds with quinone moiety in their structure, show a wide range of pharmacological activity namely antibacterial, antifungal, anticancer etc. ${ }^{[1-4]}$. The most interesting is the synthesis of compounds with antitumor activity as selective inhibitors of biological targets, epidermal growth factor receptor (EGFR), apoptosis regulator (Bcl-2), induced myeloid leukaemia cell differentiation protein (Mcl-1) and others. Derivatives of quinonecontaining compounds have been described as potential anticancer agents in several publications ${ }^{[2,5]}$. In some articles it was shown the synthesis and study of antibacterial and antifungal activity series of $\mathrm{N}-$ and $\mathrm{N}$, S-derivatives of 2,3-dichloro-1,4-naphthoquinone ${ }^{[6,7]}$. Therefore, nowadays the search and expansion of combinatorial number of compounds are necessary for further synthesis of derivatives and their biological screening.

All the chemicals were purchased from Sigma-Aldrich (USA) and were used without further purification. The

This is an open access article distributed under the terms of the Creative Commons Attribution-NonCommercial-ShareAlike 3.0 License, which allows others to remix, tweak, and build upon the work non-commercially, as long as the author is credited and the new creations are licensed under the identical terms

Accepted 11 June 2017

Revised 18 February 2017

Received 22 October 2016

*Address for correspondence

E-mail: spolovkovych@ukr.net 
reactions were monitored by pre-coated aluminium silica gel $60 \mathrm{~F}_{254}$ thin layer plates (thin layer chromatography (TLC) analysis) procured from Merck (Germany). Melting points (m.p.) were determined using an SRSEZ-Melt automated melting point instrument without correction. Infrared (IR) spectrums were recorded on a Specord-80M spectrophotometer in potassium bromide pellets. The nuclear magnetic resonance $\left({ }^{1} \mathrm{H}-\mathrm{NMR}\right.$ and ${ }^{13} \mathrm{C}-\mathrm{NMR}$ ) spectra of the compounds were recorded in deuterated dimethyl sulfoxide (DMSO- $\mathrm{d}_{6}$ ) with Varian VXR $(300 \mathrm{MHz})$ NMR spectrometer and chemical shifts were expressed in $\delta$ parts per million (ppm). Shifts reported are relative to the signal of the solvent used in each case and coupling constants are reported in $\mathrm{Hz}$ (s: singlet, bs: broad singlet, d: doublet, t: triplet, dd: double doublet, $\mathrm{m}$ : multiplet).

The procedure for the synthesis of heterocyclic derivatives of 1,4-quinones is as follows. To $0.59 \mathrm{~g}$ $(0.0026 \mathrm{~mol})$ of 2,3-dichloro-1,4-naphthoquinone 1 in $10 \mathrm{ml}$ of toluene was added $0.51 \mathrm{~g}(0.0026 \mathrm{~mol})$ 2 in the presence of equivalent amount of triethylamine $\left(\mathrm{Et}_{3} \mathrm{~N}\right)$. The reaction mass was heated to $80^{\circ}$ and stirred for $4 \mathrm{~h}$ (the reaction was monitored by TLC analysis). The precipitate was filtered off and recrystallized in dimethylformamide (DMF)/ethanol (EtOH).

2-chloro-3-\{[3-(2-methylfuran-3-yl)-5-thioxo-1, 5-dihydro-4H-1,2,4-triazol-4-yl]amino naphthalene1,4-dione (4): yield 89\%; m.p. 163-164'; Anal. calc for $\left(\mathrm{C}_{17} \mathrm{H}_{11} \mathrm{ClN}_{4} \mathrm{O}_{3} \mathrm{~S}\right), \%$ : $\mathrm{C}=52.79, \mathrm{H}=2.87, \mathrm{Cl}=9.17$, $\mathrm{N}=14.48, \mathrm{~S}=8.29$; found: $\mathrm{C}=52.75, \mathrm{H}=2.91, \mathrm{Cl}=9.14$, $\mathrm{N}=14.51, \mathrm{~S}=8.32$. IR $(\mathrm{KBr}), \mathrm{cm}^{-1}: 3224,3180,1650$ $(\mathrm{NH}), 1720,1680(\mathrm{C}=\mathrm{O}), 1450(\mathrm{C}=\mathrm{S}), 720(\mathrm{C}-\mathrm{Cl})$. ${ }^{1} \mathrm{H}$ NMR (300 MHz, DMSO-d6) $\delta$, ppm: 9.76 (bs, 1H, NH); $8.43(\mathrm{~s}, 1 \mathrm{H}, \mathrm{NH}) ; 8.04-7.74(\mathrm{~m}, 4 \mathrm{H}$, HAr); 7.68 (d, 1H, J=2.0 Hz); 6.62 (d, 1H, J=2.0 Hz); $2.52\left(\mathrm{~s}, 3 \mathrm{H}, \mathrm{CH}_{3}\right.$ ). ${ }^{13} \mathrm{CNMR}$ (DMSO) $\delta: 12.7,108.3$, $110.1,112.2,119.2,125.9,126.7,131.3,131.6,132.5$, 132.7, 134.4, 140.5, 147.3, 154.8, 167.0, 175.4, 176.4.

2-Chloro-3-\{[3-(3-methylfuran-2-yl)-5-thioxo-1,5dihydro-4H-1,2,4-triazol-4-yl]amino $\}$-naphthalene1,4-dione (6): yield 81\%; m.p. 181-182 ${ }^{\circ}$; Anal. calc for $\left(\mathrm{C}_{17} \mathrm{H}_{11} \mathrm{ClN}_{4} \mathrm{O}_{3} \mathrm{~S}\right), \%$ : $\mathrm{C}=52.79, \mathrm{H}=2.87, \mathrm{Cl}=9.17$, $\mathrm{N}=14.48, \mathrm{~S}=8.29$; found: $\mathrm{C}=52.75, \mathrm{H}=2.91, \mathrm{Cl}=9.18$, $\mathrm{N}=14.50, \mathrm{~S}=8.30$. IR (KBr), $\mathrm{cm}^{-1}: 3210,3090,1657$ $(\mathrm{NH})$, 1749, $1698(\mathrm{C}=\mathrm{O}), 1455(\mathrm{C}=\mathrm{S}), 708(\mathrm{C}-\mathrm{Cl})$. ${ }^{1} \mathrm{H}$ NMR (300 MHz, DMSO-d6) $\delta$, ppm: 9.79 (bs, $1 \mathrm{H}, \mathrm{NH}) ; 8.41$ (s, 1H, NH); 7.98-7.76 (m, 4H, HAr); 7.70 (d, 1H, J=2.0 Hz); 6.63 (d, 1H, J=2.0 Hz); 2.29 (s, $\left.3 \mathrm{H}, \mathrm{CH}_{3}\right) .{ }^{13} \mathrm{CNMR}$ (DMSO) $\delta: 11.34,116.3,124.0$,
$126.3,127.2,130.7,131.0,131.3,134.1,134.6,140.3$, $142.7,147.0,151.7,176.5,180.1$.

Heterocyclic derivatives of 1,4-quinones were synthesized by the following procedure. To $0.59 \mathrm{~g}$ $(0.0026 \mathrm{~mol}) 1 \mathrm{in} 10 \mathrm{ml}$ of EtOH was added $0.51 \mathrm{~g}$ (0.0026 mol) 2 and an equivalent amount of $\mathrm{K}_{2} \mathrm{CO}_{3}$. The reaction mass was heated to $40^{\circ}$ and stirred for $4 \mathrm{~h}$ (the reaction was monitored by TLC analysis). The precipitate was filtered off and recrystallized in DMF/ EtOH.

2- $\{[4-$ Amino-5-(2-methylfuran-3-yl)-4H-1,2, 4-triazol-3-yl]sulfanyl\}-3-chloronaphthalene-1, 4-dione (5): yield 78\%; m.p. 145-146 ${ }^{\circ}$; Anal. calc for $\left(\mathrm{C}_{17} \mathrm{H}_{11} \mathrm{ClN}_{4} \mathrm{O}_{3} \mathrm{~S}\right), \%$ : $\mathrm{C}=52.79, \mathrm{H}=2.87, \mathrm{Cl}=9.17$, $\mathrm{N}=14.48, \mathrm{~S}=8.29$; found: $\mathrm{C}=52.82, \mathrm{H}=2.86, \mathrm{Cl}=9.16$, $\mathrm{N}=14.45, \mathrm{~S}=8.24$. IR (KBr), $\mathrm{cm}^{-1}: 3550,3475\left(\mathrm{NH}_{2}\right)$, $1655(\mathrm{NH}), 1730,1690(\mathrm{C}=\mathrm{O}), 710(\mathrm{C}-\mathrm{Cl}) .{ }^{1} \mathrm{H}$ NMR (300 MHz, DMSO-d6) $\delta$, ppm: $8.12-8.00(\mathrm{~m}, 2 \mathrm{H}$, HAr); 7.85-7.79 (m, 2H, HAr); 7.74 (d, 1H, J=2.0 Hz,); $6.67(\mathrm{~d}, 1 \mathrm{H}, \mathrm{J}=2.0 \mathrm{~Hz} \text { ); } 6.27 \text { (s, 2H, NH })_{2} ; 2.54(\mathrm{~s}, 3 \mathrm{H}$, $\mathrm{CH}_{3}$ ). ${ }^{13} \mathrm{C}$ NMR (DMSO) $\delta: 12.5,106.5,110.5,112.2$, $125.7,125.9,131.3,131.5,132.7,133.8,140.5,147.0$, 155.7, 167.0, 174.3, 175.3.

2-\{[4-Amino-5-(3-methylfuran-2-yl)-4H-1,2, 4-triazol-3-yl]sulfanyl\}-3-chloronaphthalene-1, 4-dione (7): Yield 71\%; m.p. 153-154\%; Anal. calc for $\left(\mathrm{C}_{17} \mathrm{H}_{11} \mathrm{ClN}_{4} \mathrm{O}_{3} \mathrm{~S}\right), \%$ : $\mathrm{C}=52.79, \mathrm{H}=2.87, \mathrm{Cl}=9.17$, $\mathrm{N}=14.48, \mathrm{~S}=8.29$; found: $\mathrm{C}=52.83, \mathrm{H}=2.86, \mathrm{Cl}=9.16$, $\mathrm{N}=14.45, \mathrm{~S}=8.25$. IR $(\mathrm{KBr}), \mathrm{cm}^{-1}: 3545,3480\left(\mathrm{NH}_{2}\right)$, $1651(\mathrm{NH}), 1720,1680(\mathrm{C}=\mathrm{O}), 715(\mathrm{C}-\mathrm{Cl}) .{ }^{1} \mathrm{H}$ NMR (300 MHz, DMSO-d6) $\delta$, ppm: 8,12-7.98 (m, 2H, HAr); 7.87-7.71 (m, 2H, HAr); 7.72 (d, J1H, =2.0 Hz); $6.65(\mathrm{~d}, 1 \mathrm{H}, \mathrm{J}=2.0 \mathrm{~Hz}) ; 6,24\left(\mathrm{~s}, 2 \mathrm{H}, \mathrm{NH}_{2}\right) ; 2,23(\mathrm{~s}, 3 \mathrm{H}$, $\mathrm{CH}_{3}$ ). ${ }^{13} \mathrm{C}$ NMR (DMSO) $\delta: 11.34,116.3,124.0,126.3$, 127.2, 130.7, 131.0, 134.4, 134.2, 134.6, 140.3, 142.7, $147.0,151.7,176.5,180.1$.

The synthesized compounds were evaluated for antibacterial and antifungal activity against Escherichia coli B-906, Staphylococcus aureus 209-P, Mycobacterium luteum B-917, Candida tenuis VKM Y-70 and Aspergillus niger VKM F-1119 strains by the agar diffusion method ${ }^{[8]}$. Their activity was compared to that of the known antibacterial agent, vancomycin and the antifungal agent nystatin.

Antimicrobial and antifungal activity has been studied by diffusion in agar on solid nutrient medium (beefextract agar for bacteria, wort agar for fungi). Petri plates containing $20 \mathrm{ml}$ of nutrient medium were used for all the microorganisms that were tested. The 
inoculums (the microbial loading $10^{9}$ cells (spores)/ $1 \mathrm{ml}$ ) was spread on the surface of the solidified media and Whatman no. 1 filter paper discs ( $6 \mathrm{~mm}$ in diameter) impregnated with the test compound $(0.1$ and $0.5 \%)$ were placed on the plates. The duration of bacteria incubation was $24 \mathrm{~h}$ at $35^{\circ}$ and of fungi incubation $48-72 \mathrm{~h}$ at $28-30^{\circ[6]}$. The antimicrobial effect and degree of activity of the tested compounds were evaluated by measuring the zone diameters (Table 1). Control disk contained vancomicine (for bacteria) or nistatine (for fungi) as a standard. Every experiment was repeated three times.

All analyses were carried out in triplicate, and results are reported as the mean \pm standard deviation (SD). Significant differences were analysed by one-way ANOVA. Differences at $\mathrm{P}<0.05$ were considered statistically significant.

In this communication, the synthesis of a number of new condensed heterocyclic derivatives of quinone compounds has been attempted. The implementation of this approach could be carried out by appropriate interaction of $\mathrm{N}, \mathrm{S}$-bifunctional heterylaminothiotriazoles $(2,3)$ and 2,3-dichloro1,4-naphthoquinone (1) (fig. 1). Carrying out the interaction of quinone 1 with 4-amino-5-(2-methylfuran-3-yl)-2,4-dihydro- $\quad[1,2,4]$ triazole-3-thione 2 in the presence of $\mathrm{Na}_{2} \mathrm{CO}_{3}$ as the base at $30-40^{\circ}$ in DMF for $4 \mathrm{~h}$ showed that the reaction takes place

TABLE 1: EVALUATION OF RESULTS BY THE
\begin{tabular}{lc} 
METHOD OF COMPOUND DIFFUSION IN AGAR \\
\hline $\begin{array}{l}\text { Diameter of zone of } \\
\text { inhibition }(\mathrm{mm})\end{array}$ & $\begin{array}{c}\text { Degree of microorganism } \\
\text { sensitivity }\end{array}$ \\
\hline $11-15$ & Low sensitive \\
$16-25$ & Sensitive \\
$>25$ & Highly sensitive \\
\hline
\end{tabular}

with the formation of $\mathrm{N}$-nucleophilic substitution product, namely 2-chloro-3-[3-(2-methyl-furan-3-yl)5-thioxo-1,5-dihydro-[1,2,4]triazo-1-4-ylamino]-[1,4] naphthoquinone (4) and S-substitution product -2-[4-amino-5-(2-methyl-furan-3-yl)-4H-[1,2,4]triazol-3-ylsulfanyl]-3-chloro-[1,4]-naphthoquinone (5) with 35 and $43 \%$ yield, respectively.

It can be explained by the nature of selected bifunctional heterylaminothiotriazoles, for which thione-thiol tautomerism is inherent. So, in neutral solvents thione tautomeric form was dominant and in alkaline solutions, thiole was dominan ${ }^{[9-11]}$. Thereby, by selecting reaction conditions, products of $\mathrm{N}$-nucleophilic substitution and S-replacement of chlorine atom can be obtained in high yields, respectively.

The optimization of the reaction conditions was carried out in following solvents namely dioxane, EtOH, $\mathrm{MeOH}$, toluene, benzene using a number of bases $\left(\mathrm{K}_{2} \mathrm{CO}_{3}, \mathrm{Na}_{2} \mathrm{CO}_{3}, \mathrm{Et}_{3} \mathrm{~N}\right)$, at different temperatures and times of reactions (Table 2). Depending on the reaction conditions different ratio of products $\mathrm{N}$ - and S-substitution of chlorine atom there were obtained. While carrying out the interactions in DMF medium during $4 \mathrm{~h}$ highest yields were detected using as a base $\mathrm{K}_{2} \mathrm{CO}_{3}$. The highest yield of S-nucleophilic substitution product $5(89 \%)$ was obtained using $\mathrm{K}_{2} \mathrm{CO}_{3}$ at $40^{\circ}$ in EtOH during $4 \mathrm{~h}$. In other turn, the highest yield of $\mathrm{N}$-nucleophilic substitution product $4(78 \%)$ was received using $\mathrm{Et}_{3} \mathrm{~N}$, at $80^{\circ}$ in toluene during $4 \mathrm{~h}$.

Thus, the analysis of the results of investigation allowed us to obtain selective products of $\mathrm{N}$-nucleophilic substitution 4, 6 to 2,3-dichloro-1 ,4-naphthoquinone 1 in toluene was added 2 or 3 in the presence of $\mathrm{Et}_{3} \mathrm{~N}$. The reaction mass was heated and maintained at $80^{\circ}$ for $4 \mathrm{~h}$. The precipitate was filtered off and recrystallized

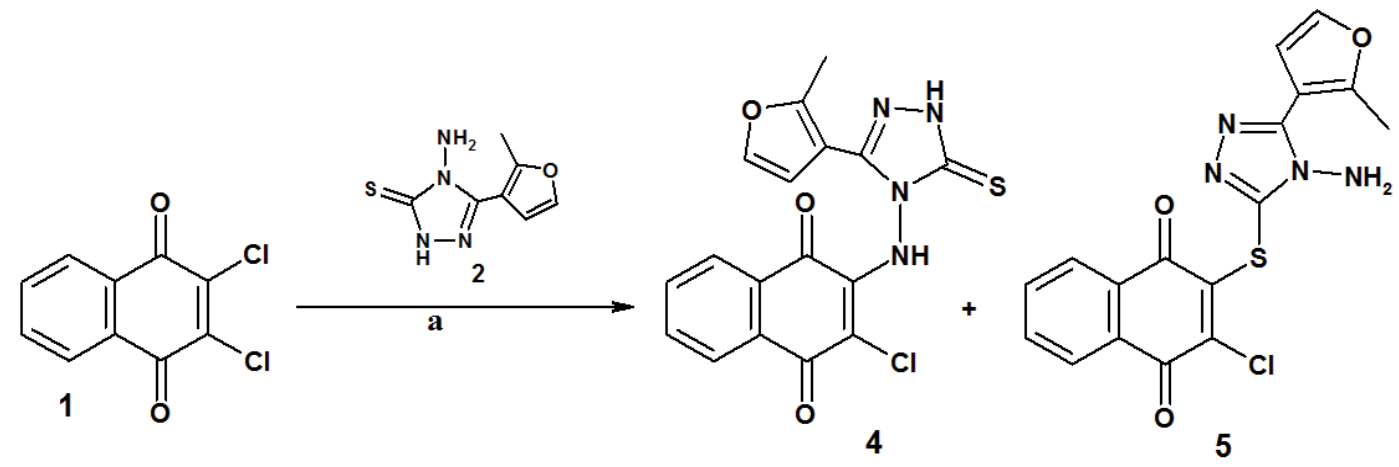

Fig. 1: Synthetic protocol of the reaction between 1,4-naphthoquinone and 4-amino-5-(2-methyl-furan-3-yl)-2,4-dihydro-[1,2,4] triazole-3-thione

(a) DMF, $\mathrm{Na}_{2} \mathrm{CO}_{3}, 30-40^{\circ}, 4$ h. (1) 2,3-dichloro-1,4-naphthoquinone; (4) 2-chloro-3-[3-(2-methyl-furan-3-yl)-5-thioxo-1,5dihydro-[1,2,4]triazo-l-4-ylamino]-[1,4] naphthoquinone; (5) 2-[4-amino-5-(2-methyl-furan-3-yl)-4H-[1,2,4]-triazol-3-ylsulfanyl]-3chloro-[1,4]-naphthoquinone 
and, respectively, S-substitution of chlorine atom 5, 7 to 2,3-dichloro-1,4-naphthoquinone 1 in EtOH was added 2 or 3 and an equivalent amount of $\mathrm{K}_{2} \mathrm{CO}_{3}$. The reaction mass was heated and maintained at $40^{\circ}$ for $2 \mathrm{~h}$. The precipitate was filtered off and recrystallized. It is reflected in the fig. 2.

It was established that the substitution of chlorine atom in the 2,3-dichloro-1,4-naphthoquinone 1 by 4-amino5-(heteryl)-2,4-dihydro-[1,2,4]triazole-3-thione 2,3 is controlled using the reaction conditions. So, in aprotic solvents there were identified only products of $\mathrm{N}$-acylation, on the other hand, in alcohols, the products of S-acylation were obtained in high yields.

Antibacterial and antifungal activity of S,Ncontaining derivatives of quinones has been studied in our laboratory previously ${ }^{[12,13]}$. Depending on the substituent, the results of antimicrobial activity of synthesized compounds differed in the degree of influence on bacteria and fungi. Analysing the data of investigations, it can be summarized that products of monosubstitution of 2,3-dichloro-1,4-naphthoquinone possess higher activity than disubstituted ones.

Piperazine-, morpholin, thio-, tert-butyl-4hydroxyphenyl substituted naphthoquinones have been already tested on strains of bacteria such as E. coli, S. aureus, M. luteum, and fungi, C. tenuis and $A$. niger. Based on the previous research it was interesting for us to synthesize compounds that combine in one molecule bifunctional heterylaminothiotriazoles and naphthoquinone moiety, and then to study their antimicrobial activity.

The synthesized compounds, 4, 5, 6, 7 were evaluated for antibacterial and antifungal activity. Results of estimate diameter of microorganism growth inhibition zones according to the parameters were listed in Table 3. Antimicrobial activity data analysis of

TABLE 2: OPTIMIZATION OF REACTION BETWEEN 1,4-NAPHTHOQUINONE AND 4-AMINO-5-(2-METHYLFURAN-3-YL)-2,4-DIHYDRO-[1,2,4] TRIAZOLE-3-THIONE

\begin{tabular}{lccccc}
\hline Solvent & \multirow{2}{*}{ Base } & \multirow{2}{*}{ Temperature $\left(^{\circ}\right)$} & \multirow{2}{*}{ Time $(\mathrm{h})$} & \multicolumn{2}{c}{ Yield, \% } \\
\cline { 3 - 6 } DMF & $\mathrm{K}_{2} \mathrm{CO}_{3}$ & $30-40$ & 4 & 28 & 57 \\
DMF & $\mathrm{Na}_{2} \mathrm{CO}_{3}$ & $30-40$ & 4 & 35 & 43 \\
Dioxane & $\mathrm{K}_{2} \mathrm{CO}_{3}$ & 40 & 4 & 0 & 69 \\
Dioxane & $\mathrm{Na}_{2} \mathrm{CO}_{3}$ & 40 & 4 & 0 & 62 \\
Ethanol & $\mathrm{K}_{2} \mathrm{CO}_{3}$ & 40 & 4 & 0 & 89 \\
Ethanol & $\mathrm{Na}_{2} \mathrm{CO}_{3}$ & 40 & 4 & 0 & 77 \\
Methanol & $\mathrm{K}_{2} \mathrm{CO}_{3}$ & 40 & 4 & 0 & 71 \\
Methanol & $\mathrm{Na}_{2} \mathrm{CO}_{3}$ & 40 & 4 & 0 & 63 \\
Toluene & $\mathrm{Et}_{3} \mathrm{~N}$ & 50 & 4 & 78 & 0 \\
Benzene & $\mathrm{Et}_{3} \mathrm{~N}$ & 80 & 4 & 65 & 0 \\
\hline
\end{tabular}

DMF: dimethylformamide

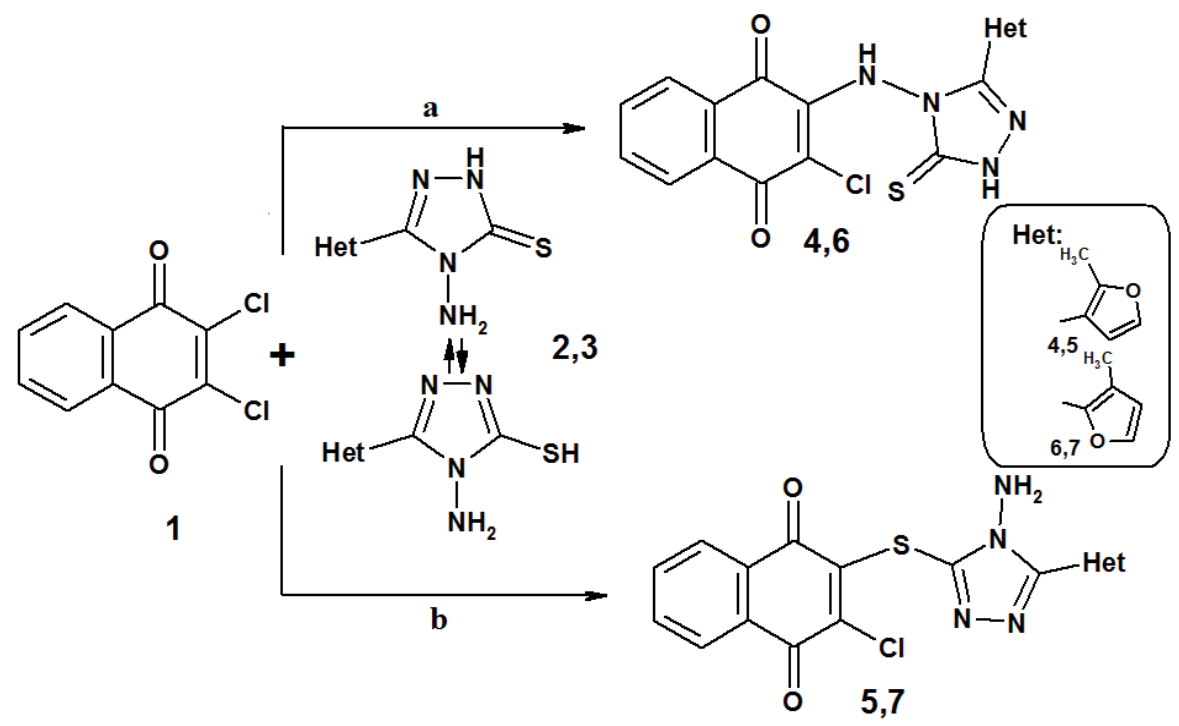

Fig. 2: Synthetic protocol for preparation of 1,4-naphthoquinone derivatives 4-6

(a) Toluene, $\mathrm{NEt}_{3}, 80^{\circ}, 4 \mathrm{~h}$; (b) EtOH, $\mathrm{K}_{2} \mathrm{CO}_{3}, 40^{\circ}, 4 \mathrm{~h}$ 


\begin{tabular}{|c|c|c|c|c|c|c|c|c|c|c|}
\hline \multirow{4}{*}{ Comp. } & \multicolumn{10}{|c|}{ Diameter of the zones of microbial growth inhibition, mm; Mean \pm SD } \\
\hline & \multicolumn{6}{|c|}{ Antibacterial activity } & \multicolumn{4}{|c|}{ Antifungal activity } \\
\hline & \multicolumn{2}{|c|}{ E. coli } & \multicolumn{2}{|c|}{ S. aureus } & \multicolumn{2}{|c|}{ M. luteum } & \multicolumn{2}{|c|}{ C. tenuis } & \multicolumn{2}{|c|}{ A. niger } \\
\hline & $0.10 \%$ & $0.50 \%$ & $0.10 \%$ & $0.50 \%$ & $0.10 \%$ & $0.50 \%$ & $0.10 \%$ & $0.50 \%$ & $0.10 \%$ & $0.50 \%$ \\
\hline 4 & 0 & 0 & $9.5 \pm 0.27$ & $15.1 \pm 0.39$ & $9.5 \pm 0.43$ & $11.8 \pm 0.41$ & 0 & $10.8 \pm 0.25$ & $6.8 \pm 0.50$ & $12.1 \pm 0.53$ \\
\hline 5 & 0 & 0 & $10.4 \pm 0.21$ & $16.4 \pm 0.43$ & $9.7 \pm 0.35$ & $16.9 \pm 0.49$ & 0 & $9.9 \pm 0.35$ & 0 & $10.5 \pm 0.58$ \\
\hline 6 & 0 & 0 & $10.2 \pm 0.34$ & $16.2 \pm 0.43$ & 0 & $11.1 \pm 0.43$ & 0 & $10.5 \pm 0.55$ & 0 & $11.2 \pm 0.57$ \\
\hline 7 & 0 & 0 & $10.7 \pm 0.30$ & $16.5 \pm 0.47$ & $14.6 \pm 0.39$ & $17.2 \pm 0.45$ & $8.5 \pm 0.57$ & $12.1 \pm 0.45$ & $6.6 \pm 0.35$ & $11.9 \pm 0.51$ \\
\hline$C^{*}$ & 0 & $14 \pm 0.34$ & $11.3 \pm 0.34$ & $16.6 \pm 0.43$ & $15.8 \pm 0.41$ & $17.7 \pm 0.47$ & $11.3 \pm 0.51$ & $19.0 \pm 0.51$ & $7.7 \pm 0.50$ & $20.1 \pm 0.58$ \\
\hline
\end{tabular}

All analyses were carried out in triplicate, and results are reported as the mean \pm standard deviation (SD). C*: vancomycin was used as a control in the tests of antibacterial activity of the synthesized compounds, and nystatin was used in the tests of antifungal activity

heterocyclic quinoid derivative series showed that studied microorganisms were predominantly insensitive to the synthesized derivatives. The compounds $4,5,6$, 7 had good activity against $S$. aureus at a concentration of $0.1 \%$ and $0.5 \%$. The strain $M$. luteum was most sensitive to compounds 5,7 at a concentration of $0.5 \%$. The compounds 4, 5, 6, 7 had low antibacterial activity against $C$. tenuis and $A$. niger and had no antibacterial activity against $E$. coli at 0.1 and $0.5 \%$ concentration evaluated by the diffusion method. The results obtained are presented in Table 3.

Optimized conditions of interaction showed that the reaction could be controlled in following ways. In aprotic solvents, only $\mathrm{N}$-acylation products were obtained and in alcohols -S-acylation products that in general is a subject of Kornblum's rule. Investigation of antimicrobial activity of the synthesized compounds showed that cultures of E. coli, A. niger and C. tenuis are practically not sensitive to 1,4-naphthoquinone heterocyclic derivatives $4,5,6,7$, but showed medium to high activity value to $S$. aureus and $M$. luteum. Thus, compounds 5, 7 have found to possess high antibacterial activity with respect to these cultures.

\section{Financial assistance:}

None.

\section{Conflict of interests:}

None declared.

\section{REFERENCES}

1. Phillips RM, Jaffar M, Maitland DJ. Pharmacological and biological evaluation of a series of substituted 1,4-naphthoquinone bioreductive drugs. Biochem Pharmacol 2004;68:2107-16.

2. Tandon VK, Singh RV, Yadav DB. Synthesis and evaluation of novel 1,4-naphthoquinone derivatives as antiviral, antifungal and anticancer agents. Bioorg Med Chem Lett 2004;14:2901-04.
3. Chung Y, Yoo J. Dependence of antitumor activity on the electrophilicity of 2-substituted 1,4-naphthoquinone derivatives. Bull Korean Chem Soc 2007;28:691-94.

4. Polovkovych S, Dumanska Yu, Syngaevsky V, Shakh Y, Konechna R, Marshalok $\mathrm{O}$, et al. Chemical reaction of 5-substituted 1,4-naphthoquinones with crotonaldehyde$\mathrm{N}, \mathrm{N}$-dimethylhydrazone and investigation of derived compounds antimicrobial activity. Res J Pharm Biol Chem Sci 2016;7:2125-34.

5. Zhao LM, Xie TP, He YQ, Xu DF, Li SS. Synthesis and antitumor activity of 6- and 2-(1-substituted-thio-4methylpent-3-enyl)-5,8-dimethoxynaphthalene-1,4-diones. Eur J Med Chem 2009;44:1410-14.

6. Ibis C, Sahinler Ayla S, Bahar H, Stasevych M, KomarovskaPorokhnyavets O, Novikov V. Synthesis, Characterization, and Biological Properties of Novel Piperidinolyl-, Piperidinyl-, and Piperazinyl-Substituted Naphthoquinone Compounds and Their Reactions With Some Thiols. Phosphorus Sulfur Silicon Relat Elem 2015;190:1422-33.

7. Ibis C, Tuyun A, Sahinler Ayla S, Bahar H, Stasevych M, Musyanovych R, et al. Synthesis of novel 1,4-naphthoquinone derivatives: Antibacterial and antifungal agents. Med Chem Res 2013; 22:2879-88.

8. Murray PR, Baron EJ, Pfaller MA, Tenover FC, Yolken RH. Manual of clinical microbiology. 6th ed. Washington: ASM Press;1995. p. 1327-41.

9. Siwek A, Wujec M, Wawrzycka-Gorczyca I, Dobosz M, Paneth P. Thiol-thione tautomeric forms recognition on the example of 4-[3-(2-Methyl-furan-3-yl)-5-thioxo-1,2,4triazolin-4-yl] acetic acid. Heteroat Chem 2008;19:337-44.

10. Koparır M, Çetin A, Cansız A. 5-Furan-2yl[1,3,4]oxadiazole2-thiol, 5-Furan-2yl-4H [1,2,4]triazole-3-thiol and Their Thiol-Thione Tautomerism. Molecules 2005;10:475-80.

11. Kothari P, Mehlhoff M, Singh S, Parmar S, Stenberg V. Synthesis of 5-(1-naphthylmethyl)-4-aryl-s-triazol-3-thiols/ yl-thioglycolic acids as possible antiinflammatory agents. . J Heterocycl Chem 1980;17:1369-72.

12. Deniz NG, Ibis C, Gokmen Z, Stasevych M, Novikov V, Komarovska-Porokhnyavets $\mathrm{O}$, et al. Design, synthesis, biological evaluation, and antioxidant and cytotoxic activity of heteroatom-substituted 1,4-naphtho- and benzoquinones. Chem Pharm Bull 2015;63:1029-39.

13. Figurka OM, Yaremkevych OSv, Gubriy ZV, Khomyak SV, Novikov VP. Synthesis and properties of 3-amino-2-(3,5di-tert-buthyl-4-hydroxyphenil)-1,4-naphthoquinones. Bulg Chem Commun 2016;48:141-46. 